\title{
Allegations of bias cloud conflicting reports on bisphenol A's effects
}

Bisphenol A is found in everything from plastic baby bottles to the liners of tin cans - and it may or may not be bad for you.

Since the mid-1990s, the estrogen-like chemical has been the focus of an escalating, ugly debate between two groups of scientists. One ๖ group has argued vehemently that the chemical is dangerous and must be banned even as the other, equally vigorously, has defended its safety.

In late July, a group of scientists published a report concluding that exposure to even low levels of bisphenol, particularly during development, can cause serious reproductive problems (Reprod. Toxicol., doi:10.1016/ j.reprotox.2007.07.005).

But less than two weeks later, an independent panel assembled to advise the US government expressed "negligible concern for adverse reproductive effects."

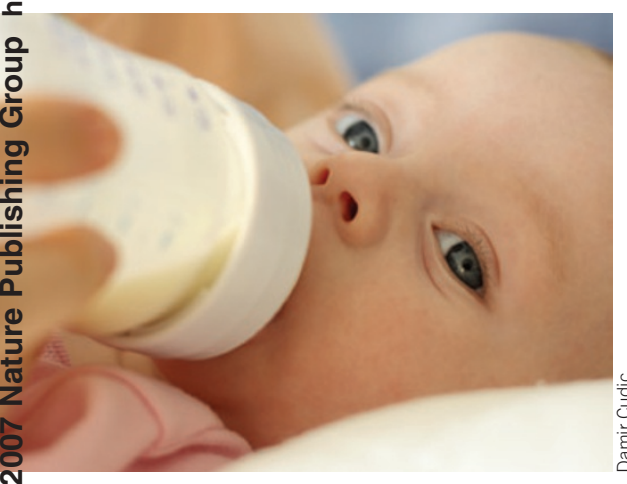

Hidden menace? Experts sharply disagree on whether bisphenol A, found in many consumer products such as baby bottles, is safe.
The public disagreement has incited accusations of bias on both sides and left consumers bewildered. Should they avoid the chemical? Or not?

"It's certainly confusing and I wish it weren't," says Michael Shelby, director of the US National Toxicology Program's (NTP) Center for the Evaluation of Risks to Human Reproduction, which convened the government panel. "According to the panel results, if there is concern, it's not great," Shelby says.

Critics have accused the government panel of industry bias, forcing the NTP in April to dismiss a contractor that had ties to the chemical industry. The US Environmental Protection Agency has also come under fire for considering scientists with conflicts of interest to assess the safety of acrylamide, a neurotoxin found in fried and baked goods.

Some experts also question the government panel's methods, in particular the decision to exclude as sources of information more than half of the 124 papers published on bisphenol A's effects on development.

"I was shocked," says Beverly Rubin, a bisphenol A expert at Tufts University in Boston. "[The review] was bizarre, sloppy and very arbitrary. They discounted a lot of very good work and then left in a lot of work that's not so good."

What's more, the panel accepted $70 \%$ of industry-funded papers, but only $30 \%$ of those from academia, notes Ana Soto, a developmental biologist at Tufts. "Why would they do that?" Soto asks. "It's mind-boggling."
Richard Chapin, a researcher at the pharmaceutical company Pfizer and chair of the advisory panel, denies allegations of industry influence. "We established scientifically valid criteria and then we held those up to each study in turn," he says.

Chapin says Soto and others may be too passionate to be scientifically rigorous. "This might be a case where people are putting advocacy before science," Chapin says.

Some of the uncertainty about bisphenol $\mathrm{A}$ is the result of a dearth of human studies, which have to last through the long lag time between exposure and any effects. The National Children's Study, scheduled to begin next year, aims to follow 100,000 American children from the womb until age 21 , and will assess exposure to bisphenol A as well as to heavy metals, pesticides and other pollutants. But the first results won't emerge for at least five years.

The NTP is also not likely to have an official position on bisphenol A for at least six months. In the meantime, Shelby recommends that those consumers who are concerned should switch to bisphenol A-free alternatives, such as glass baby bottles instead of plastic, and fresh and frozen foods as opposed to canned goods.

Kimberly Thompson, a risk analysis expert at Harvard University, advocates that individuals become informed so that they can assess their own risk. "[But] it's very tricky," she says. "People really do rely on experts to understand whether they should or shouldn't be concerned."

Cassandra Willyard, New York

\section{DDT's ability to repel mosquitoes trumps resistance, scientists say}

The notorious pesticide dichloro-diphenyltrichloroethane (DDT), maligned for decades because of its alleged effect on ecosystems, is highly effective at repelling mosquitoes that are resistant to it, according to a new study published in August.

Malaria prevention programs have chosen pesticides for their ability to killnot deter-mosquitoes. But a pesticide that repels mosquitoes can also be used against those that are resistant to it, making it a more attractive option.

Faced with malaria's unrelenting death toll, particularly in Africa and in some parts of Asia, international agencies last year renewed support for DDT (Nat. Med. $12,870-871 ; 2006)$. The insecticide is now one of 12 recommended for indoor residual spraying by the World Health Organization's malaria program.

Anti-DDT campaigns launched by environmental groups in the 1970 s had led the US and many European countries to ban the pesticide's use. Its return last year met with criticism from environmentalists and from scientists who noted that mosquitoes have developed resistance to the chemical.

The new study lays that latter criticism to rest (PLOS ONE 2, e716; 2007).

"If the primary action of the insecticide is not to kill but to repel, then it can remain effective," says Richard Tren, director of Africa Fighting Malaria, a Washington, DC-based nonprofit health advocacy group that advocates DDT use and that publicized this study.
Based on the study, the researchers propose a new classification system for insecticides that considers their repellent, irritant and toxic effects.

In their work, the researchers studied DDT-resistant strains of Aedes aegypti mosquitoes, which transmit dengue and yellow fever, but not malaria. They looked at how the mosquitoes responded to three different insecticides: dieldrin, alphacypermethrin and DDT.

In huts sprayed with dieldren, $92 \%$ of mosquitoes that touched the chemical died. Mosquitoes exposed to alphacypermethrin became irritated after making contract with the chemical and quickly left the hut or died, effectively reducing the number of mosquitoes that can transmit disease by $61 \%$. 